Article

\title{
Impaired Platelet Aggregation and Rebalanced Hemostasis in Patients with Chronic Hepatitis C Virus Infection
}

\author{
Nick S. Nielsen ${ }^{1}$, Sofie Jespersen ${ }^{1}$, Julie C. Gaardbo ${ }^{1}$, Caroline J. Arnbjerg ${ }^{1}$, Mette R. Clausen ${ }^{2}$, \\ Mette Kjær ${ }^{2}$, Jan Gerstoft ${ }^{1}$, Vibe Ballegaard ${ }^{1}$, Sisse R. Ostrowski ${ }^{3}$ and Susanne D. Nielsen ${ }^{1, *}$ \\ 1 Department of Infectious Diseases, University Hospital of Copenhagen, Rigshospitalet, 2100 København, \\ Denmark; nick@nielsen.mail.dk (N.S.N.); sofie.dikeledi@gmail.com (S.J.); juliegaardbo@hotmail.com (J.C.G.); \\ caroline.arnbjerg@gmail.com (C.J.A.); Jan.Gerstoft@regionh.dk (J.G.); vibececilie@gmail.com (V.B.) \\ 2 Department of Hepatology, University Hospital of Copenhagen, Rigshospitalet, 2100 København, Denmark; \\ anne.mette.rye.clausen@regionh.dk (M.R.C.); mette.skalshoei.kjaer@regionh.dk (M.K.) \\ 3 Department of Clinical Immunology, University Hospital of Copenhagen, Rigshospitalet, 2100 København, \\ Denmark; sisse.ostrowski@gmail.com \\ * Correspondence: sdn@dadlnet.dk; Tel.: +45-35-45-08-59; Fax: +45-35-45-66-48
}

Academic Editor: Akihiro Tamori

Received: 3 March 2017; Accepted: 4 May 2017; Published: 8 May 2017

\begin{abstract}
Increased risk of both cardiovascular disease (CVD) and bleeding has been found in patients with chronic hepatitis $\mathrm{C}(\mathrm{CHC})$ infection, and a re-balanced hemostasis has been proposed. The aim of this study was to investigate functional whole blood coagulation and platelet function in CHC infection. The prospective study included 82 patients with CHC infection ( 39 with advanced liver fibrosis and 43 with no or mild liver fibrosis) and 39 healthy controls. A total of 33 patients were treated for $\mathrm{CHC}$ infection and achieved sustained virological response (SVR). Baseline and post-treatment blood samples were collected. Hemostasis was assessed by both standard coagulation tests and functional whole blood hemostatic assays (thromboelastograhy (TEG), and platelet aggregation (Multiplate). Patients with CHC and advanced fibrosis had impaired platelet aggregation both compared to patients with no or mild fibrosis and to healthy controls. Patients with CHC and advanced fibrosis also had lower antithrombin, platelet count, and coagulation factors II-VII-X compared to healthy controls. In contrast, TEG did not differ between groups. In treated patients achieving SVR, post-treatment platelet count was higher than pre-treatment counts $(p=0.033)$ and ADPtest, ASPItest, and RISTOhightest all increased post treatment (all $p<0.05)$. All Multiplate tests values, however, remained below those in the healthy controls. CHC-infected patients displayed evidence of rebalanced hemostasis with only partly hemostatic normalization in patients achieving SVR. The implications of rebalanced hemostasis and especially the impact on risk of CVD and bleeding warrants further studies.
\end{abstract}

Keywords: HCV; hemostasis; platelet aggregation

\section{Introduction}

Hepatitis $\mathrm{C}$ virus (HCV) is the cause of viral hepatitis, with an estimated 130-150 million persons with chronic hepatitis $\mathrm{C}$ infection (CHC) worldwide [1]. Approximately $80 \%$ of those infected will develop $\mathrm{CHC}$, and $10-15 \%$ of patients with $\mathrm{CHC}$ infection will develop advanced liver disease with cirrhosis and increased risk of hepatocellular carcinoma (HCC) [2]. Besides these well-known manifestations of $\mathrm{CHC}$, increased risk of cardiovascular disease (CVD) and thromboembolic events has been documented [3-6]. Vascular inflammation and altered coagulation caused by $\mathrm{CHC}$ infection has been hypothesized to contribute to increased CVD risk. In contrast, $\mathrm{CHC}$ infection is also associated 
with thrombocytopenia and lower levels of coagulation factors, contributing to an increased risk of bleeding [7-9]. Evidence thus points towards manifestations of both hypo- and hypercoagulability.

Hemostasis is balanced by pro- and anticoagulant and pro- and antifibrinolytic factors, most of these being synthesized by the liver [10]. Advanced liver disease is thus associated with perturbations in the level of these due to secretory deficiencies [11,12]. Furthermore, lower platelet count, lower concentrations of factor II-VII-X, and anti-fibrinolytic factors are all features of CHC infection, suggesting hypocoagulability $[7,10,13]$. However, higher concentrations of von-Willebrand factor (vWf) and Factor VIII as well as lower concentrations of anticoagulant factors including Protein C and $\mathrm{S}$ have also been reported in $\mathrm{CHC}$ infection suggesting hypercoagulability [10,13-15]. The combination of these alterations may lead to a rebalanced hemostasis as a common explanation for the observed increased risk of both thromboembolic events and bleeding in patients with CHC infection [13].

Conventional plasma-based coagulation tests such as activated partial thromboplastin time (APTT) and international normalized ratio (INR) are often used to assess both hemostasis and liver function in CHC-infected patients [16]. However, these tests are poor predictors of bleeding risk and cannot predict thrombotic events [16]. In contrast, the risk of bleeding and thromboembolic events can be assessed by functional hemostatic whole blood tests such as thromboelastography (TEG) and impedance platelet aggregometry (Multiplate), which are well-established tests reflecting secondary and primary hemostasis, respectively $[13,15,17]$. To the present authors' knowledge, no previous studies have investigated whole blood hemostatic function in patients with $\mathrm{CHC}$ infection.

The primary aim of this study was to investigate hemostasis in patients with $\mathrm{CHC}$ infection using functional hemostatic whole blood tests and determine possible associations with liver fibrosis. CHC-infected patients with no or mild and with advanced fibrosis as well as a group of uninfected controls were included in a cross sectional study. To determine possible effects of HCV viral replication on coagulation, a prospective study of patients starting treatment against $\mathrm{CHC}$ infection was conducted. It was hypothesized that untreated $\mathrm{CHC}$ infection was associated with altered whole blood functional hemostasis tests and that hemostasis would normalize after successful treatment of HCV.

\section{Results}

The three groups (CHC with no or mild fibrosis, $\mathrm{CHC}$ with advanced fibrosis, and healthy controls) in the cross sectional study differed regarding age (Table 1). A Spearman correlation test did not reveal any significant correlations between age and TEG or Multiplate data. Furthermore, due to study design, the CHC-infected group with advanced fibrosis had a higher level of fibrosis compared to patients with no or mild fibrosis (Table 1).

\subsection{Altered Standard Coagulation Tests in CHC-Infected Patients}

Compared to healthy controls, patients with $\mathrm{CHC}$ infection, both with no or mild fibrosis and with advanced fibrosis, had lower platelet counts and lower concentration of antithrombin, whereas only patients with advanced fibrosis had lower concentration of coagulation factor II-VII-X (Table 2).

Compared to CHC-infected patients with no or mild fibrosis, CHC-infected patients with advanced fibrosis had lower platelet counts (median $139 \times 10^{9} / \mathrm{L}$ versus 232 platelets $\times 10^{9} / \mathrm{L}$, $p<0.001)$ and lower concentration of coagulation factors ( 0.76 arb.units versus 0.88 arb.units, $p=0.002$ ). Furthermore, the concentration of antithrombin was lower in patients with advanced fibrosis compared to patients with only no or mild fibrosis $(0.86 \mathrm{IU} / \mathrm{L}$ versus $1.01 \mathrm{IU} / \mathrm{L}(p<0.001))$. The proportion of patients with D-dimer above threshold was $21 \%$ in the group of CHC-infected patients with advanced fibrosis versus $2 \%$ in CHC-infected patients with no or mild fibrosis $(p=0.009)$. APTT and fibrinogen did not differ between CHC-infected patients (Table 2). A sub-group analyses of patients with cirrhosis (Fibroscan $>12 \mathrm{kPa}$ or F4 verified with biopsy) vs. no or mild fibrosis is shown in Table S1, and results are comparable to advanced fibrosis versus no or mild fibrosis presented in Table 2. 
Table 1. Data are shown as medians (IQR) or $n(\%)$. Groups were compared with Mann-Whitney-U or chi-square test as appropriate. The indicated $p$-value represents the comparison between $\mathrm{CHC}$-infected patients with no or mild fibrosis and with advanced fibrosis. IV, Intravenous; $\mathrm{HCV}$, Hepatitis $\mathrm{C}$ virus; $\mathrm{CHC}$, Chronic Hepatitis C; kPa, Kilopascal.

\begin{tabular}{|c|c|c|c|c|c|}
\hline Baseline Characteristics & $\begin{array}{l}\text { HCV Infected with No or } \\
\text { Mild Fibrosis }(n=43)^{*}\end{array}$ & $\begin{array}{c}\text { HCV Infected with } \\
\text { Advanced Fibrosis }(n=39)\end{array}$ & $\begin{array}{l}\text { Healthy Controls } \\
\quad(n=39)\end{array}$ & $p$-Value & HCV Infected + Treatment $(n=33)$ \\
\hline Gender, $n$ (Male) $(\mathrm{m} \%)$ & $27(62.8)$ & $23(59)$ & $20(51.3)$ & 0.495 & $21(61.8)$ \\
\hline Age, year, median (IQR) & $49(37-56)$ & $57(50-61) \mathrm{L}$ & $51(42-56)$ & 0.001 & $55(45-60)$ \\
\hline Current smoker $n(\%)$ & $18(42)^{\mathrm{L}}$ & $15(38)$ & $10(25)$ & 0.358 & $18(53)$ \\
\hline HCV-RNA at inclusion, IU/mL, median, (IQR) & $1.2 \times 10^{6}\left(0.28 \times 10^{6}-3.00 \times 10^{6}\right)$ & $1.6 \times 10^{6}\left(0.68 \times 10^{6}-4.05 \times 10^{6}\right)$ & N/A & 0.166 & $1.55 \times 10^{6}\left(0.8 \times 10^{6}-3.8 \times 10^{6}\right)$ \\
\hline Years since diagnosis of HCV infection, median (IQR) & $14(6-23)$ & $10(3-27)$ & N/A & 0.266 & $11(5-25)$ \\
\hline Genotype $1 / 2 / 3 / 4 n$ & $22 / 8 / 9 / 3$ & $18 / 2 / 16 / 3$ & N/A & N/A & $20 / 1 / 12 / 1$ \\
\hline Fibroscan $\mathrm{kPa}$, median $(\mathrm{IQR})$ & $5.7(4.7-6.2)$ & $14.1(11.1-21.3)$ & N/A & $<0.001$ & $13.5(6.6-20.2)$ \\
\hline Bilirubin level, $\mu \mathrm{mol} / \mathrm{L}$, median (IQR) & $7(6-10)$ & $11(6-16)$ & N/A & 0.009 & $11(6-16)$ \\
\hline Albumin level, g/L, median (IQR) & $39(37-40)$ & $37(34-38)$ & N/A & 0.002 & $36(34-38)$ \\
\hline Creatinine level, $\mu \mathrm{mol} / \mathrm{L}$, medicn $(\mathrm{IQR})$ & $75(68-86)$ & $68(61-80)$ & N/A & 0.068 & $70(62-82)$ \\
\hline INR, median (IQR) & $1.1(1.1-1.2)$ & $1.1(1.1-1.2)^{\mathrm{L}}$ & $1.0(1.0-1.1)$ & 0.002 & $1.1(1.0-1.2)$ \\
\hline $\begin{array}{l}\text { Patients with presence of portal hypertension } \\
\text { / esophagal varices at enrollment }(n)\end{array}$ & & $5 / 2$ & & & $4 / 2$ \\
\hline Treatment used, $n \mathrm{~A}(\mathrm{r}+) / \mathrm{B}(\mathrm{r}+) / \mathrm{C}(\mathrm{r}+) / \mathrm{D}(\mathrm{r}+) / \mathrm{E}(\mathrm{r}+)$ & & & & & $5(2) / 17(10) / 5(0) / 3(0) / 3(1)$ \\
\hline Treatment duration, $n 8 / 12 / 16 / 24$ weeks & & & & & $8 / 19 / 3 / 3$ \\
\hline
\end{tabular}

Treatment regimens: (A): sofosbuvir/simeprevir; (B): sofosbuvir/daclatasvir; (C): grazoprevir/MK-3682/MK-8408; (D): grazoprevir/MK-3682/elbasvir; (E): sofos
$\left(\mathrm{r}+\right.$ ) indicating number of patients receiving the regimen including ribavirin. ${ }^{*} 1$ case without reported HCV genotype. ${ }^{\mathrm{L}} p<0.05$ by comparison with healthy controls. 
Table 2. Data are presented as median (IQR) with $\mathrm{p}$ values reflecting differences between CHC-infected patients with advanced or with no or mild fibrosis. The two groups were compared Mann-Whitney $U$ test. Detection limit for D-dimer was $0.3 \mathrm{FEU} / 1$. D-dimer was divided into groups according to whether the individual was above or below threshold and the two groups were compared with chi-square test. The indicated p-value represents comparison between HCV infected patients with advanced and with no or mild fibrosis; arb.units, arbitrary units; $\mathrm{CHC}$, Chronic Hepatitis C; FEU, Fibrinogen equivalent units; $\mathrm{U}$, Units. ${ }^{\mathrm{L}} p<0.05$ by comparison with healthy controls.

\begin{tabular}{|c|c|c|c|c|c|}
\hline Coagulation Tests & Normal Range & HCV Infected with Advanced Fibrosis & HCV Infected with no or Mild Fibrosis & $p$-Value & Healthy Controls \\
\hline \multicolumn{6}{|l|}{ Standard coagulation tests } \\
\hline Platelet count, median (IQR) & $145-390 \times 10^{9}$ cells $/ \mathrm{L}$ & $139(113-187)^{\mathrm{L}}$ & $232(184-267)^{\mathrm{L}}$ & $<0.001$ & $254(230-293)$ \\
\hline Coagulation factors II-VII-X, median (IQR) & $>0.60$ arb.units/L & $0.76(0.6-0.86)^{\mathrm{L}}$ & $0.88(0.76-1.03)$ & 0.002 & $0.93(0.81-1.06)$ \\
\hline D-dimer, median (IQR) & $>0.5 \mathrm{mg} \mathrm{FEU} / \mathrm{L}$ & $0.3(0.3-0.4)^{\mathrm{L}}$ & $0.3(0.3-0.3)$ & 0.002 & $0.3(0.3-0.3)$ \\
\hline Above threshold, $n(\%)$ & & $8(21)^{\mathrm{L}}$ & $1(2)$ & 0.009 & $0(0)$ \\
\hline Antithrombin, median (IQR) & $0.83-1.15 \times 10^{3} \mathrm{IU} / \mathrm{L}$ & $0.86(0.7-0.92)^{\mathrm{L}}$ & $1.01(0.95-1.11)^{\mathrm{L}}$ & 0.001 & $1.10(1.05-1.16)$ \\
\hline APTT, median (IQR) & $25-37 \mathrm{~s}$ & $28(26-30)$ & $28(27-30)$ & 0.738 & $29(28-31)$ \\
\hline Fibrinogen, median (IQR) & $5.3-10.3 \mu \mathrm{mol} / \mathrm{L}$ & $8.5(7.6-10)$ & $8.1(7.1-9.5)^{\mathrm{L}}$ & 0.333 & $8.7(8.1-10.2)$ \\
\hline \multicolumn{6}{|l|}{ Whole blood functional hemostasis tests } \\
\hline $\mathrm{R}$, median (IQR) & $4-9 \min$ & $6,7(5.7-7.9)$ & $6.4(5.5-7.5)$ & 0.239 & $6.8(5.8-7.6)$ \\
\hline Angle, median (IQR) & $55-78$ degrees & $65(61-68)$ & $67(64-69)$ & 0.122 & $67(62-69)$ \\
\hline MA, median (IQR) & $51-69 \mathrm{~mm}$ & $58(54-61)$ & $61(57-63)$ & 0.044 & $52(56-66)$ \\
\hline Ly30, \%, median (IQR) & $0-4 \%$ & $0.9(0.0-2.6)$ & $1.4(0.2-3.2)$ & 0.393 & $1.6(0.3-4.0)$ \\
\hline
\end{tabular}




\subsection{Normal Functional Whole Blood Hemostasis in CHC-Infected Patients}

Whole blood hemostasis assed by TEG did not differ between patients with CHC infection and healthy controls (Table 2). However, TEG MA values were lower in CHC-infected patients with advanced fibrosis compared to CHC-infected patients with no or mild fibrosis (58 versus $61 \mathrm{~mm}$, $p=0.04$ ). R time, Angle, and Ly30 did not differ between any of the groups (Table 2).

\subsection{Impaired Whole Blood Platelet Aggregation in Patients with CHC Infection}

Patients with $\mathrm{CHC}$ infection and advanced fibrosis had impaired platelet aggregation assessed by Multiplate when compared to both CHC-infected patients with no or mild fibrosis and healthy controls (Table 2). TRAP results for CHC-infected patients with advanced fibrosis was 79 units versus 98 units in patients with no or mild fibrosis $(p=0.003)$ and 116 units in the healthy controls $(p<0.001)$. Same pattern was observed for ADP, ASPI and RISTOhigh analysis (Figure 1).

A

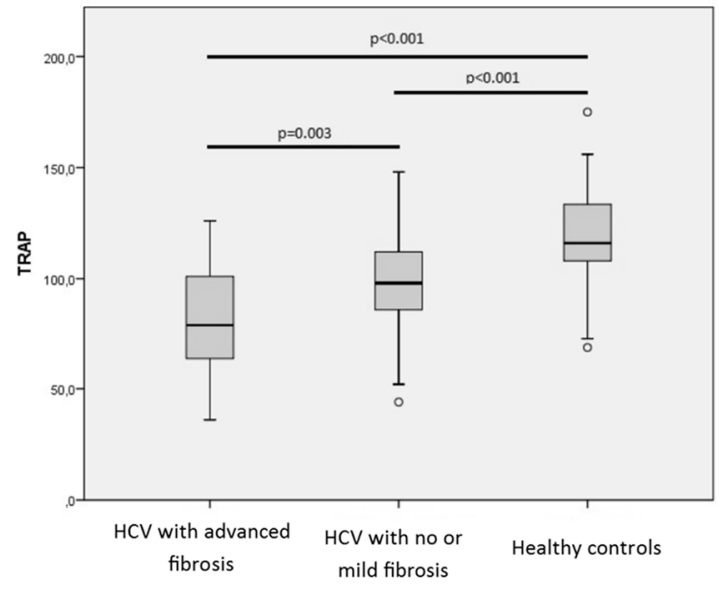

C

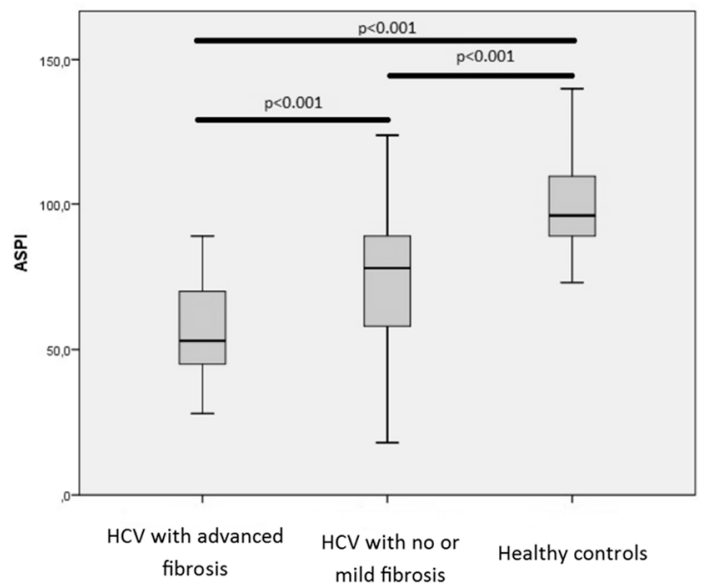

B

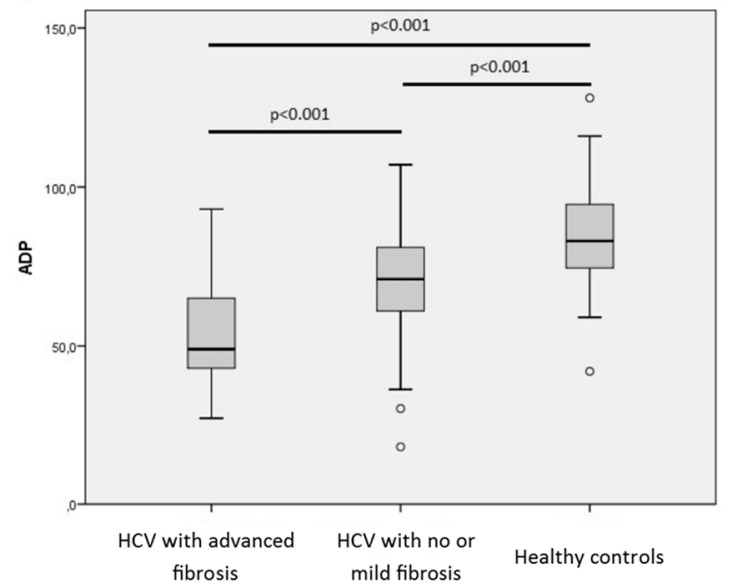

D

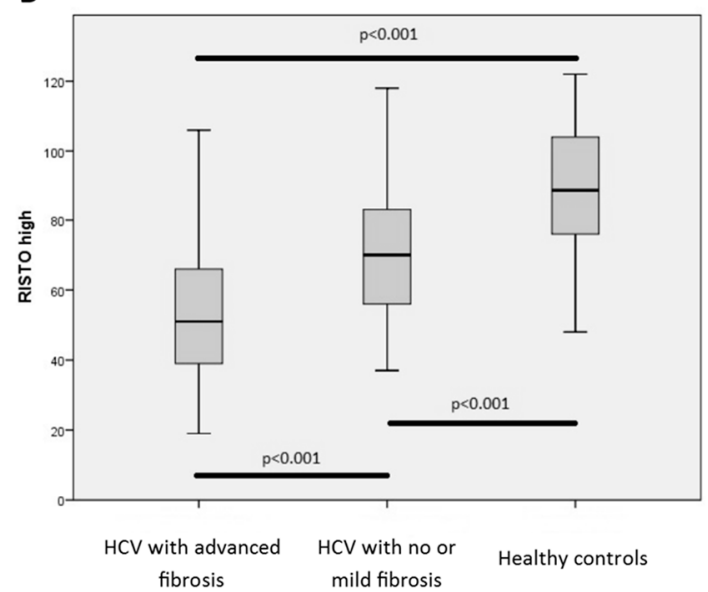

Figure 1. Results from Multiplate analysis preformed on included patient (HCV with no or mild fibrosis $n=43$ and HCV with advanced fibrosis $n=39)$ and healthy controls $(n=39)$. Boxplot indicating upper and lower quartile (IQR) and median. Whiskers indicating upper and lower extreme. (A): TRAP analysis; (B): ADP analysis; (C): ASPI analysis; (D): RISTO high analysis. $p$-values indicate comparison of the groups using Mann-Whitney $U$ test.

When correcting for platelet count ("multiplate variable" /"platelet count in patient" = multiplate unit per platelet), patients with advanced fibrosis had higher per platelet function than both $\mathrm{CHC}$-infected patients with no or mild fibrosis (TRAP/platelet count $=0.51$ versus $0.42 \mathrm{U} / 10^{9} / \mathrm{L}$ 
$p=0.008$ ) and healthy controls (TRAP/platelet count $=0.51$ versus $0.46 \mathrm{U} / 10^{9} / \mathrm{L} p=0.044$ ). Same pattern was observed for ADPtest but not ASPItest and RISTOhigh test (data not shown).

\subsection{Minor Changes in Functional Hemostasis after Treatment}

A total of 33 patients were treated for CHC infection and achieved SVR. End of treatment samples were compared with baseline samples. Standard blood coagulation tests, platelet counts, and fibrinogen were partly but not fully restored and remained below the healthy controls (Table 3). No changes in overall wholeblood coagulation (TEG analysis) were found (Table 3).

Table 3. Data from 33 patients undergoing 8-24 weeks of treatment against CHC virus infection. Data are presented as medians (IQR) with $\mathrm{p}$ values reflecting the difference between blood results before and after treatment. The results were compared using Wilcoxon test. arb.units, arbitrary units; CHC, Chronic Hepatitis C; FEU, Fibrinogen equivalent units; U, Units. ${ }^{\mathrm{L}} p<0.05$ by comparison with healthy controls.

\begin{tabular}{ccccc}
\hline $\begin{array}{c}\text { Coagulation in CHC-Infected Patients } \\
\text { before and after Treatment against HCV }\end{array}$ & Pre Treatment & Post Treatment & $p$-Value & Healthy Controls \\
\hline Standard coagulation tests & & & & \\
Platelet count, median (IQR) & $166(113-209)^{\mathrm{L}}$ & $170(118-230)^{\mathrm{L}}$ & 0.033 & $254(230-293)$ \\
Coagulation factors II-VII-X, median (IQR) & $0.79(0.63-0.86)^{\mathrm{L}}$ & $0.73(0.62-0.90)^{\mathrm{L}}$ & 0.837 & $0.93(0.81-1.06)$ \\
D-dimer, median (IQR) & $0.3(0.3-0.4)^{\mathrm{L}}$ & $0.3(0.3-0.4)^{\mathrm{L}}$ & 0.495 & $0.3(0.3-0.3)$ \\
Above threshold (\%) & $5(14)^{\mathrm{L}}$ & $4(12)^{\mathrm{L}}$ & & $0(0)$ \\
Antithrombin, median (IQR) & $0.88(0.73-1.05)^{\mathrm{L}}$ & $0.93(0.80-0.98)^{\mathrm{L}}$ & 0.865 & $1.10(1.05-1.16)$ \\
APTT, median (IQR) & $29(27-30)$ & $28(26-31)$ & 0.116 & $29(28-31)$ \\
Fibrinogen, median (IQR) & $8.2(7.2-10.1)$ & $9.6(8.4-10.7)$ & 0.001 & $8.7(8.1-10.2)$ \\
Whole blood functional hemostasis tests & & & & \\
R, median (IQR) & $6.6(5.8-7.6)$ & $6.4(5.5-7.2)$ & 0.543 & $6.8(5.8-7.6)$ \\
Angle, median (IQR) & $65(60-67)$ & $66(60-69)$ & 0.294 & $67(62-69)$ \\
MA, median (IQR) & $58(54-61)$ & $59(54-64)$ & 0.058 & $52(56-66)$ \\
Ly30, \%, median (IQR) & $0.8(0.7-2.4)$ & $1.2(1.2-3.4)$ & 0.808 & $1.6(0.3-4.0)$ \\
\hline
\end{tabular}

Improvements were observed in the Multiplate analysis with partly normalization of ( $p=0.003)$, ASPItest $(p=0.007)$, and RISTOhigh test $(p=0.003)$. No significant differences were observed in the TRAPtest $(p=0.060)$ (Figure 2). When correcting for platelet count, the per platelet function did not significantly change post treatment when compared to pretreatment (TRAP/platelet count $=0.51$ versus $\left.0.49 \mathrm{U} / 10^{9} / \mathrm{L} p=0.537\right)$. The same pattern was observed for ADPtest, ASPItest, and RISTOhigh test (data not shown).

Compared to uninfected controls, patients who had been treated for $\mathrm{CHC}$ infection and achieved SVR still had lower platelet count $(p=0.001)$ and coagulation factor II-VII-X ( $p=0.001)$. In contrast whole blood hemostasis was comparable to uninfected control (Table 3). Importantly, patients with SVR still had impaired platelet aggregation with lower TRAPtest $(p=0.001)$ ADPtest $(p=0.001)$, ASPItest $(p=0.001)$, and RISTOhigh test $(p=0.004)$ when compared to healthy controls (Figure 2$)$. Patients who achieved SVR continued to have significant lower per platelet activation in TRAP analysis post treatment when compared to healthy controls (TRAP/platelet $=0.49$ versus $0.46 \mathrm{U} / 10^{9} / \mathrm{L} p=0.027$ ). Same pattern was observed for ADPtest $(p=0.001)$ and RISTOhigh test $(p=0.036)$ but not ASPItest $(p=0.270)$. 


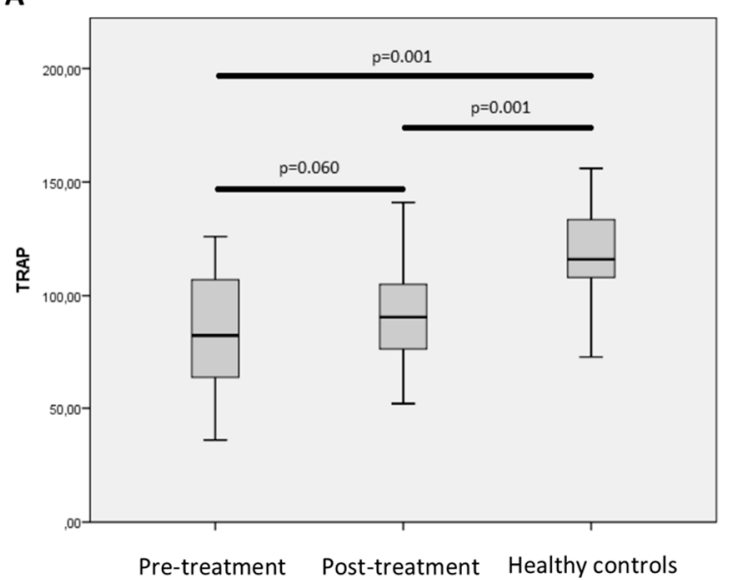

C

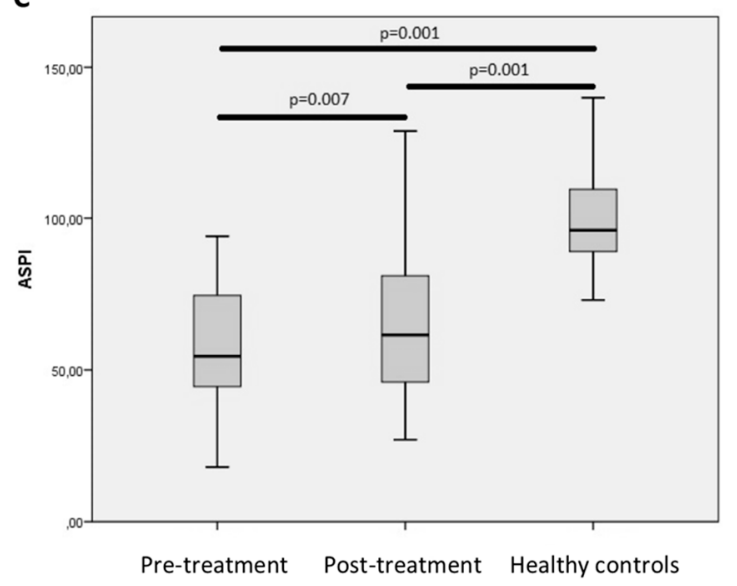

B

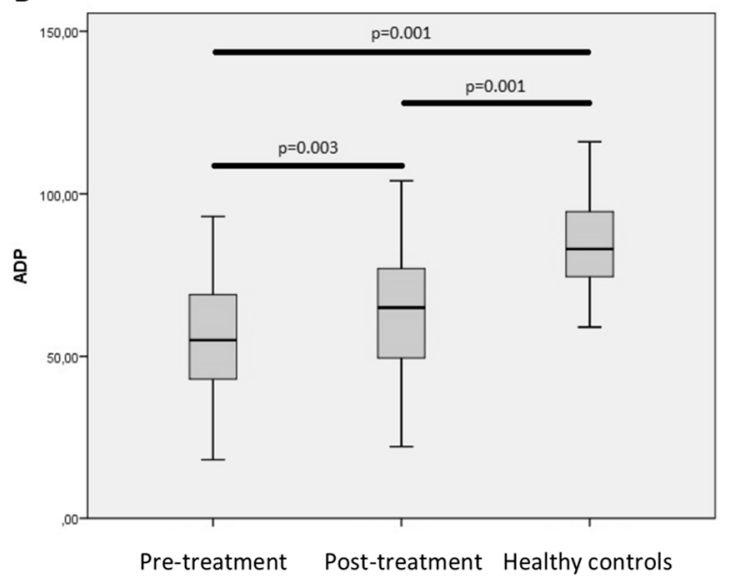

D

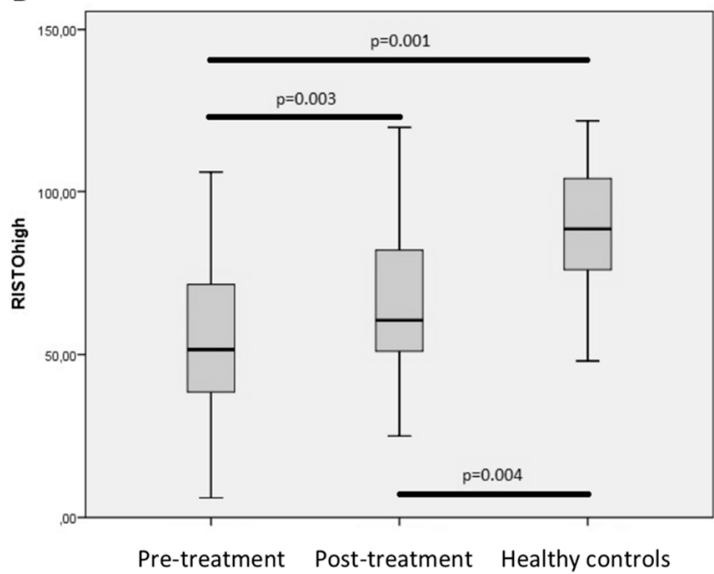

Figure 2. Results from Multiplate analysis preformed on included patient who received treatment against chronic hepatitis $C$ infection and who achieved sustained virological response $(n=33)$. Compared with Multiplate analysis preformed on healthy controls $(n=39)$. Boxplot indicating upper and lower quartile (IQR) and median. Whiskers indicating upper and lower extreme. (A): TRAP analysis; (B): ADP analysis; (C): ASPI analysis; (D): RISTO high analysis. $p$-values indicate comparison of the groups using Wilcoxon test or Mann-Whitney $U$ test as appropriate.

\section{Discussion}

Patients with CHC infection and advanced fibrosis had decreased platelet count and impaired platelet aggregation when compared to both $\mathrm{CHC}$ patients with no or mild fibrosis and healthy controls. However, patients with $\mathrm{CHC}$ infection and advanced fibrosis also displayed evidence of no overall impairment in functional hemostasis indicating a rebalanced overall hemostatic capacity Importantly, CHC-infected patients that were treated and achieved SVR only obtained partial normalization of both platelets count and platelet aggregation, when compared to the healthy controls.

Coagulation in patients with $\mathrm{CHC}$ infection has often been evaluated using standard coagulation tests including factor II-VII-X, INR, and APTT. However, the use of these tests in patients with liver disease has been questioned as the tests are poor predictors of both bleeding and cardiovascular comorbidity $[5,16]$. The accumulating evidence of increased risk of thromboembolic events and CVD in patients with CHC infection warrants application of tests that measure functional hemostatis $[16,18]$. TEG has been used for a decade to monitor and goal-direct hemostatic therapy in liver transplantation, cardiac surgery, intensive care, and bleeding in trauma patients [19-23]. TEG has also been used to predict cardiovascular events like pulmonary embolism, myocardial infarction, and deep vein thrombosis (DVT) in post-surgical patients $[19,21,24,25]$ and to evaluate risk of bleeding in patients 
with liver disease $[16,26]$. Studies have found an overall normal TEG in patients with liver disease, further suggesting a rebalanced hemostasis [27]. Multiplate has been used in clinical routine to monitor the effect of anti-platelet drugs in surgical settings and platelet dysfunction in critical illness including trauma and sepsis $[17,28,29]$ as well as to evaluate risk of cardiovascular events and effect of antithombotic medication [30-32]. Thus, whole blood functional hemostasis tests may provide additional information about hemostasis and CVD risk in CHC-infected patients. At the University Hospital of Copenhagen, TEG and Multiplate are used to goal-direct transfusion and therapy with pro-hemostatic drugs in bleeding or at risk of bleeding patients and in patients prior to high risk surgical procedures [33]. The present study does not assess the possible benefits of using TEG and/or Multiplate in CHC patients in a surgical setting; further studies are needed to assess this aspect. Using whole blood coagulation test, especially Multiplate, could prove valuable in the clinical assessment of liver disease, especially when complicated with bleeding, but further studies are needed aiming to investigate this $\mathrm{CHC}$ patients.

Assessing fibrosis using fibroscan to is feasible, but exact cut-off for fibrosis and cirrhosis are still a matter of debate. According to the European Association for the Study of the Liver (EASL) guidelines, values between 5.2 and $9.5 \mathrm{kPa}$ have been proposed as cut-off for $\geq \mathrm{F} 2$ fibrosis and values between 11.9 and $14.8 \mathrm{kPa}$ as cut-off for cirrhosis [34]. Based on these guidelines and guidelines from our clinic, the present study divided patients with $\mathrm{CHC}$ infection in two groups. One with Fibroscan $<8 \mathrm{kPa}$ termed "CHC patients with no or mild fibrosis level" and one with Fibroscan $>8 \mathrm{kPa}$ termed "CHC patients with advanced fibrosis" including cirrhosis.

The prevalence of thrombocytopenia in patients with chronic liver disease, including CHC, has been reported to be between $15-70 \%$, with thrombocytopenia being associated with the severity of disease $[7,35]$. In agreement with this, the present study found lower platelet counts in patients with advanced fibrosis as compared to patients with no or mild fibrosis. Furthermore, patients with advanced fibrosis had impaired platelet aggregation compared to patients with no or mild fibrosis and healthy controls. Likewise, previous studies of platelet function in $\mathrm{CHC}$, applying the platelet function analyzer (PFA-100) and quantitative measurements of metabolites from the platelet metabolism, have suggested a dysfunction of platelets in patients with advanced liver disease [36-38]. Thus, impaired function of platelets in patients with cirrhosis due to impaired inositol lipid and arachidonic acid metabolism has been reported [38]. Furthermore, lower platelet activation in patients with hepatitis B and $C$ was found after stimulated with TRAP but not ADP [39]. Interestingly, the present study found higher per-platelet activation in patients with advanced fibrosis compared to that in healthy controls suggesting a compensatory mechanism in patients with advanced liver disease. The present study, however, does not provide information on the exact mechanism for such a compensation, and further studies are needed to explore this subject.

Previous studies have found impairment of both the pro- and anticoagulant system in patients with chronic liver disease, including $\mathrm{CHC}$ infection, and a hypothesis suggesting a rebalanced coagulation has been proposed [9,13-15]. The present study provides support for this hypothesis. Thus, despite having lower platelet count, impaired overall platelet aggregation, and lower concentration of pro-coagulant factors, patients with $\mathrm{CHC}$ infection had normal whole blood functional hemostasis when measured with TEG. This suggests that CHC-infected patients have a rebalanced hemostatic system possible partly due to lower levels of antithombin and by higher per-platelet activity found in present study.

The effect of HCV viral replication on coagulation was assessed in a prospective study of 33 patients that were treated for CHC infection and achieved SVR. Only minor changes were observed in standard coagulation parameters post treatment. Thus, although platelet counts and level of coagulation factor II-VII-X increased post treatment, they remained lower compared to healthy controls. A previous study including 100 patients with SVR showed a slow rise and only gradual normalization in platelet count over 7.5 years of follow up. [40]. Likewise, improvement of platelet aggregation was found in post treatment though it did not reach a level comparable with that in healthy controls. 
This calls into question whether altered coagulation in CHC infection is merely a direct result of HCV viral replication. An alternative explanation could be damage to the liver as evidenced by the presence of persistent liver fibrosis in patients with SVR. Earlier studies have suggested a slow regression of fibrosis in some but not all patients who achieve SVR [41-45]. Unfortunately, this study was not able to measure the level of fibrosis post treatment. However, the above suggests a long recovery phase beyond that of achieving SVR, indicating the need to evaluate the functional hemostatic system in studies with longer follow-up.

The present study had some limitations. First, it included a relatively low number of participants especially in the prospective study. The cross-sectional design used in part of the study limits analysis of causality. Treated patients only had one blood sample drawn post treatment, limiting the possible effects of long-term SVR on the coagulation system and unfortunately patients with or without fibrosis differed with regards to age. However, significant correlations between age and the functional hemostasis tests were not found. Finally, all hemostasis tests were performed on blood in vitro, not taking the contribution of the endothelium into account.

\section{Methods}

\subsection{Patients}

A cross-sectional study was conducted including 82 CHC-infected patients $(n=39$ with advanced fibrosis and $n=43$ with no or mild fibrosis) and 39 uninfected controls. The patients were recruited from The Department of Infectious Diseases and The Department of Hepatology, Copenhagen University Hospital, Rigshospitalet during the period September 2014 to June 2015. The sample size was based on a pre-study power calculation. According to reference intervals the median $R$ value is $7.4 \mathrm{~min}$ (SD 1.6). According to the power calculation, the required number of participants should be 41 in order to detect a difference of $1 \mathrm{~min}$ with a power $80 \%$ and $\alpha$ of 0.05 . We therefore aimed at including 41 in each group. Inclusion criteria were age $\geq 18$ years, documented $\mathrm{CHC}$ infection, and compensated Child Pugh A. Fibrosis was determined using fibroscan or biopsy (cut off for no or mild fibrosis using fibroscan $>8 \mathrm{kPa}$ and for biopsy F1 or greater). A total of 31 patients included in the study had a Fibroscan value $>12 \mathrm{kPa}$ or a biopsy verified fibrosis level F4, indicating presence of cirrhosis. Exclusion criteria were anticoagulant or antithrombotic therapy, congenital hemostatic diseases including hemophilia, Hepatitis B infection, HIV infection, and autoimmune disease. Clinical characteristics for patients and controls are presented in Table 1.

The prospective study included 36 patients from the cross sectional study who initiated treatment for $\mathrm{CHC}$ infection. All patients were treated between eight and 24 weeks. Type and duration of treatment are shown in Table 1. At time of enrolment into the present study, 8 patients who underwent treatment against CHC, was enrolled in a clinical trial of direct acting antivirals (DAA) (MK-3682-011 and MK-3682-012). The participation in the present study did not influence participation in other studies. During treatment, two patients were diagnosed with HCC and one patient did not achieve sustained virological response (SVR). These three patients were excluded from further analyzes. Thus, the prospective cohort included 33 patients that all achieved SVR (Table 1).

The study was approved by The Committee on Biomedical Research Ethics for the Capital Region in Denmark (H-1-2014-064) and the Danish Data Protection Agency and conducted in accordance with the Second Declaration of Helsinki. Written informed consent was obtained from all participants.

\subsection{Blood Sampling}

All participants had a $30 \mathrm{~mL}$ venous blood sample taken at study entry. Patients included in the prospective study had an additional $30 \mathrm{~mL}$ venous blood sample taken at end of treatment. 


\subsection{Conventional Plasma Based and Functional Haemostatic Whole-Blood Tests}

Routine biochemistry was analysed in a DS/EN ISO 15189 standardized laboratory and included D-dimer, fibrinogen (Clauss method), APTT, combined coagulation factors II-VII-X (Q hemostasis, Medinor, Denmark), antithrombin (ACL TOP, ILS, Allerod, Denmark), and platelet count (XE-2100; Sysmex, Kobe, Japan).

\subsection{Tromboelastography (TEG)}

Clot formation was assessed in 3.2\% citrated whole blood (BD, Franklin Lakes, Bergen County, NJ, USA) within two hours of sampling using a TEG 5000 Haemostasis Analyzer System (Haemonetics Corp, Braintree, MA, USA) according to manufacturer's recommendations. Variables recorded were (reference range reported by Haemonetics Corp are given in square brackets) reaction time ( $\mathrm{R}(4-9 \mathrm{~min})$, reflecting rate of initial fibrin formation), angle $\left(\alpha\left(55-78^{\circ}\right)\right.$, clot growth kinetics, reflecting thrombin burst), maximum amplitude (MA (51-69 mm), reflecting maximum clot strength), and lysis after $30 \mathrm{~min}$ (Ly30 (0-4\%), proportional reduction in amplitude after MA, reflecting fibrinolysis. Day-to-day coefficient of variation of TEG MA is $<7 \%$ in our laboratory.

\subsection{Impedance Aggregometry (Multiplate)}

Whole blood platelet aggregation was analyzed in heparin anticoagulated blood by impedance aggregometry using a Multiple Platelet function Analyzer (Multiplate ${ }^{\circledR}$ analyzer, Software Version 2.02.11, Dynabyte GmbH, Munich, Germany), assessing aggregation after stimulation with adenosinediphosphate test(ADPtest), arachidonic acid (ASPItest), ristocetin in high concentration (RISTOtest), and thrombin receptor agonist peptide (TRAPtest) according to manufacturer's recommendations. Platelet aggregation was determined in response to commercially available test reagents (Dynabyte $\mathrm{GmbH}$, Munich, Germany). Samples were analyzed within 30-120 min of blood sampling. All Multiplate reagents and disposables were obtained from Triolab AS (Brøndby, Denmark). Briefly, $300 \mu \mathrm{L}$ whole blood was mixed with $300 \mu \mathrm{L} \mathrm{NaCl}$ (ASPItest) or $\mathrm{NaCl}^{-\mathrm{CaCl}_{2}}$ (TRAPtest, ADPtest), and $20 \mu \mathrm{L}$ platelet agonist (TRAPtest (TRAP)-6, final concentration $32 \mu \mathrm{M}$ ), ADPtest (ADP, $6.5 \mu \mathrm{M})$, RISTOtest $(0.77 \mathrm{mg} / \mathrm{mL})$ and ASPItest $(0.5 \mathrm{mM}))$. Increase in impedance by attachment of platelets onto Multiplate sensors is transformed to arbitrary aggregation units (AU) and plotted against time. For each applied platelet agonist, the area under the aggregation curve (AUC, AU $\times$ min or $\mathrm{U}(1 \mathrm{U}=10 \mathrm{AU} \times \mathrm{min}))$ after $6 \mathrm{~min}$ analysis was recorded by the Multiplate analyser. In order to assess platelet function "per platelet," Multiplate result was divided by platelet count.

\subsection{Statistics and Data}

Data were analysed by SPSS Statistics 22 (IBM SPSS Statistics, Armonk, NY, USA). All data is available from authors on request. As data were not normally distributed, non-parametric tests were used. The groups included in the study (CHC with advanced or with no or mild fibrosis and uninfected controls; CHC patients before and after treatment) were compared by Mann-Whitney $U$ test, Wilcoxon signed rank test, or Chi-square test/Fishers exact test as appropriate. Due to significant difference in age between groups, a Spearman correlation was performed to identify possible correlation between age and the outcomes of the study. $p$-values below 0.05 were considered to be statistical significant.

\section{Conclusions}

In conclusion, this study found evidence for a rebalanced hemostasis in patients with $\mathrm{CHC}$ infection. Although having lower platelet count, impaired platelet aggregation, and lower coagulation factor II-VII-X, CHC-infected patients had normal whole blood coagulation test (TEG), possibly due to lower levels of antithombin and higher per-platelet activity, suggested by the data. Only partly normalization of platelet count, concentration of factor II-VII-X, antithrombin, and platelet activation were observed in patients achieving SVR. The implications of a rebalanced hemostasis and especially 
the impact on risk of CVD and bleeding warrants further studies in larger cohorts and with longer follow up.

Supplementary Materials: Supplementary materials can be found at www.mdpi.com/1422-0067/18/5/1016/s1.

Acknowledgments: The authors acknowledge the support of a pre-graduate grant from the Danish council for independent research (DFF-4092-00150); The Novo Nordisk foundation, University Hospital of Copenhagen, Rigshospitalet. The authors gratefully acknowledge all patients and healthy controls that participated in the study.

Author Contributions: Nick S. Nielsen, Julie C. Gaardbo, Sofie Jespersen, Jan Gerstoft, Sisse R. Ostrowski and Susanne D. Nielsen designed the study. Nick S. Nielsen, Sofie Jespersen, Caroline J. Arnbjerg, Mette R. Clausen, Mette Kjær and Susanne D. Nielsen included the patients and were involved in data collection. Nick S. Nielsen, Vibe Ballegaard and Susanne D. Nielsen preformed the statistical analysis. All authors interpreted the data. Nick S. Nielsen drafted the manuscript. All authors have critically reviewed and approved the manuscript.

Conflicts of Interest: Jan Gerstoft received money paid to his institution from Merck Sharp \& Dohme Corp (MSD), Gilead, Abbvie, Medivir, Bristol -Myers Squibb (BMS), and Viiv. Susanne D. Nielsen performed advisory board activity for Gilead and GlaxoSmithKline (GSK). All other authors declare no conflict of interest.

$\begin{array}{ll}\text { Abbreviations } \\ \text { CVD } & \text { Cardiovascular disease } \\ \text { CHC } & \text { Chronic Hepatitis C } \\ \text { HCV } & \text { Hepatitis C virus } \\ \text { SVR } & \text { Sustained Virological Response } \\ \text { TEG } & \text { Tromboelastography } \\ \text { HCC } & \text { Hepatocellular carcinoma } \\ \text { vWF } & \text { Von Willebrand factor } \\ \text { APTT } & \text { Activated partial thromboplastin time } \\ \text { INR } & \text { International normalized ratio } \\ \text { HIV } & \text { Human immunodeficiency virus } \\ \text { DAA } & \text { Direct-acting antivirals } \\ \text { DVT } & \text { Deep vein thrombosis } \\ \text { EASL } & \text { European Association for the Study of the Liver }\end{array}$

\section{References}

1. World Health Organization (WHO). Hepatitis C; WHO: Geneva, Switzerland, 2014.

2. Chen, S.L.; Morgan, T.R. The natural history of hepatitis c virus (HCV) infection. Int. J. Med. 2006, 3, 47-52. [CrossRef]

3. Zampino, R.; Marrone, A.; Restivo, L.; Guerrera, B.; Sellitto, A.; Rinaldi, L.; Romano, C.; Adinolfi, L.E. Chronic HCV infection and inflammation: Clinical impact on hepatic and extra-hepatic manifestations. World J. Hepatol. 2013, 5, 528-540. [PubMed]

4. Vassalle, C.; Masini, S.; Bianchi, F.; Zucchelli, G.C. Evidence for association between hepatitis C virus seropositivity and coronary artery disease. Heart 2004, 90, 565-566. [CrossRef] [PubMed]

5. Butt, A.A.; Wang, X.; Budoff, M.; Leaf, D.; Kuller, L.H.; Justice, A.C. Hepatitis c virus infection and the risk of coronary disease. Clin. Infect. Diseases 2011, 49, 225-232. [CrossRef] [PubMed]

6. Ampuero, J. Assessing cardiovascular risk in hepatitis c: An unmet need. World J. Hepatol. 2015, 7, 2214. [CrossRef] [PubMed]

7. Fouad, Y.M. Chronic hepatitis c-associated thrombocytopenia: Aetiology and management. Trop. Gastroenterol. 2013, 34, 58-67. [CrossRef] [PubMed]

8. Sherman, K.E. Advanced liver disease: What every hepatitis c virus treater should know. Top. Antivir. Med. 2011, 19, 121-125. [PubMed]

9. Lisman, T.; Leebeek, F.W.G. Hemostatic alterations in liver disease: A review on pathophysiology, clinical consequences, and treatment. Dig. Surg. 2007, 24, 250-258. [CrossRef] [PubMed]

10. Lisman, T. Hemostatic dysfunction in liver diseases. Semin. Thromb. Hemost. 2015, 445-446. [CrossRef] [PubMed] 
11. Northup, P.G.; Caldwell, S.H. Coagulation in liver disease: A guide for the clinician. Clin. Gastroenterol. Hepatol. 2013, 11, 1064-1074. [CrossRef] [PubMed]

12. Tripodi, A.; Mannucci, P.M. The coagulopathy of chronic liver disease. N. Engl. J. Med. 2011, 365, 147-156. [CrossRef] [PubMed]

13. Lisman, T.; Porte, R.J. Rebalanced hemostasis in patients with liver disease: Evidence and clinical consequences. Blood 2010, 116, 878-885. [CrossRef] [PubMed]

14. Lisman, T.; Bongers, T.N.; Adelmeijer, J.; Janssen, H.L.A.; de Maat, M.P.M.; de Groot, P.G.; Leebeek, F.W.G. Elevated levels of von willebrand factor in cirrhosis support platelet adhesion despite reduced functional capacity. Hepatology 2006, 44, 53-61. [CrossRef] [PubMed]

15. Hollestelle, M.J.; Geertzen, H.G.M.; Straatsburg, I.H.; Gulik, T.M.V.; Mourik, J.A.V. Factor VIII expression in liver disease. Thromb. Haemost. 2004, 91, 267-275. [CrossRef] [PubMed]

16. Mallett, S.V.; Chowdary, P.; Burroughs, A.K. Clinical utility of viscoelastic tests of coagulation in patients with liver disease. Liver Int. 2013, 33, 961-974. [CrossRef] [PubMed]

17. Görlinger, K.; Jambor, C.; Hanke, A.A.; Dirkmann, D.; Adamzik, M.; Hartmann, M.; Rahe-Meyer, N. Perioperative coagulation management and control of platelet transfusion by point-of-care platelet function analysis. Transf. Med. Hemother. 2007, 34, 396-411. [CrossRef]

18. Mannucci, P.M. Abnormal hemostasis tests and bleeding in chronic liver disease: Are they related? No. J. Thromb. Haemost. 2006, 4, 721-723. [CrossRef] [PubMed]

19. Cotton, B.A.; Minei, K.M.; Radwan, Z.A.; Matijevic, N.; Pivalizza, E.; Podbielski, J.; Wade, C.E.; Kozar, R.A.; Holcomb, J.B. Admission rapid thrombelastography predicts development of pulmonary embolism in trauma patients. J. Trauma Acute Care Surg. 2012, 72, 1470-1475. [CrossRef] [PubMed]

20. Kashuk, J.L.; Moore, E.E.; Sabel, A.; Barnett, C.; Haenel, J.; Le, T.; Pezold, M.; Lawrence, J.; Biffl, W.L.; Cothren, C.C.; et al. Rapid thrombelastography (r-teg) identifies hypercoagulability and predicts thromboembolic events in surgical patients. Surgery 2009, 146, 764-772. [CrossRef] [PubMed]

21. Dai, Y.; Lee, A.; Critchley, L.A.H.; White, P.F. Does thromboelastography predict postoperative thromboembolic events? A systematic review of the literature. Anesth. Analg. 2009, 108, 734-742. [CrossRef] [PubMed]

22. McCrath, D.J.; Cerboni, E.; Frumento, R.J.; Hirsh, A.L.; Bennett-Guerrero, E. Thromboelastography maximum amplitude predicts postoperative thrombotic complications including myocardial infarction. Anesth. Analg. 2005, 100, 1576-1583. [CrossRef] [PubMed]

23. Müller, M.C.; Meijers, J.C.; Vroom, M.B.; Juffermans, N.P. Utility of thromboelastography and/or thromboelastometry in adults with sepsis: A systematic review. Crit. Care 2014, 18, 1-11. [CrossRef] [PubMed]

24. Dickinson, K.J.; Troxler, M.; Homer-Vanniasinkam, S. The surgical application of point-of-care haemostasis and platelet function testing. Br. J. Surg. 2008, 95, 1317-1330. [CrossRef] [PubMed]

25. Rafiq, S.; Johansson, P.I.; Ostrowski, S.R.; Stissing, T.; Steinbrüchel, D.A. Hypercoagulability in patients undergoing coronary artery bypass grafting: Prevalence, patient characteristics and postoperative outcome. Eur. J. Card. Thorac. Surg. 2012, 41, 550-555. [CrossRef] [PubMed]

26. Tripodi, A.; Primignani, M.; Chantarangkul, V.; Viscardi, Y.; Dell'Era, A.; Fabris, F.M.; Mannucci, P.M. The coagulopathy of cirrhosis assessed by thromboelastometry and its correlation with conventional coagulation parameters. Thromb. Res. 2009, 124, 132-136. [CrossRef] [PubMed]

27. Stravitz, R.T. Potential applications of thromboelastography in patients with acute and chronic liver disease. Gastroenterol. Hepatol. 2012, 8, 513-520.

28. Gurbel, P.A.; Bliden, K.P.; Guyer, K.; Cho, P.W.; Zaman, K.A.; Kreutz, R.P.; Bassi, A.K.; Tantry, U.S. Platelet reactivity in patients and recurrent events post-stenting. J. Am. Coll. Cardiol. 2005, 46, 1820-1826. [CrossRef] [PubMed]

29. Paniccia, R.; Priora, R.; Liotta, A.A.; Abbate, R. Platelet function tests: A comparative review. Vasc. Health Risk Manag. 2015, 11, 133-148. [CrossRef] [PubMed]

30. Sibbing, D.; Braun, S.; Morath, T.; Mehilli, J.; Vogt, W.; Schömig, A.; Kastrati, A.; von Beckerath, N. Platelet reactivity after clopidogrel treatment assessed with point-of-care analysis and early drug-eluting stent thrombosis. J. Am. Coll. Cardiol. 2009, 53, 849-856. [CrossRef] [PubMed] 
31. Sibbing, D.; Morath, T.; Braun, S.; Stegherr, J.; Mehilli, J.; Vogt, W.; Schomig, A.; Kastrati, A.; von Beckerath, N. Clopidogrel response status assessed with multiplate point-of-care analysis and the incidence and timing of stent thrombosis over six months following coronary stenting. Thromb. Haemost. 2010, 103, 151-159. [CrossRef] [PubMed]

32. Paarup Dridi, N.; Johansson, P.I.; Lønborg, J.T.; Clemmensen, P.; Radu, M.D.; Qayyum, A.; Pedersen, F.; Kollslid, R.; Helqvist, S.; Saunamäki, K.; et al. Tailored antiplatelet therapy to improve prognosis in patients exhibiting clopidogrel low-response prior to percutaneous coronary intervention for stable angina or non-st elevation acute coronary syndrome. Platelets 2015, 26, 521-529. [CrossRef] [PubMed]

33. Johansson, P.I.; Stensballe, J.; Oliveri, R.; Wade, C.E.; Ostrowski, S.R.; Holcomb, J.B. How I treat patients with massive hemorrhage. Blood 2014, 124, 3052-3058. [CrossRef] [PubMed]

34. European Association for Study of Liver; Asociacion Latinoamericana para el Estudio del Higado. EASL-ALEH clinical practice guidelines: Non-invasive tests for evaluation of liver disease severity and prognosis. J. Hepatol. 2015, 63, 237-264.

35. Giannini, E.G. Review article: Thrombocytopenia in chronic liver disease and pharmacologic treatment options. Aliment. Pharmacol. Ther. 2006, 23, 1055-1065. [CrossRef] [PubMed]

36. Tripodi, A.; Primignani, M.; Chantarangkul, V.; Clerici, M.; Dell’Era, A.; Fabris, F.; Salerno, F.; Mannucci, P.M. Thrombin generation in patients with cirrhosis: The role of platelets. Hepatology 2006, 44, 440-445. [CrossRef] [PubMed]

37. Escolar, G.; Cases, A.; Vinas, M.; Pino, M.; Calls, J.; Cirera, I.; Ordinas, A. Evaluation of acquired platelet dysfunctions in uremic and cirrhotic patients using the platelet function analyzer (pfa-100): Influence of hematocrit elevation. Haematologica 1999, 84, 614-619. [PubMed]

38. Laffi, G.; Cominelli, F.; Ruggiero, M.; Fedi, S.; Chiarugi, V.P.; La Villa, G.; Pinzani, M.; Gentilini, P. Altered platelet function in cirrhosis of the liver: Impairment of inositol lipid and arachidonic acid metabolism in response to agonists. Hepatology 1988, 8, 1620-1626. [CrossRef] [PubMed]

39. Alkozai, E.M.; Porte, R.J.; Adelmeijer, J.; Zanetto, A.; Simioni, P.; Senzolo, M.; Lisman, T. No evidence for increased platelet activation in patients with hepatitis b- or c-related cirrhosis and hepatocellular carcinoma. Thromb. Res. 2014, 135, 292-297. [CrossRef] [PubMed]

40. Koh, C.; Heller, T.; Haynes-Williams, V.; Hara, K.; Zhao, X.; Feld, J.J.; Kleiner, D.E.; Rotman, Y.; Ghany, M.G.; Liang, T.J.; et al. Long term outcome of chronic hepatitis c after sustained virological response to interferon-based therapy. Aliment. Pharmacol. Ther. 2013, 37, 887-894. [CrossRef] [PubMed]

41. Serfaty, L. Follow-up of patients with chronic hepatitis c and a sustained viral response. Liver Int. 2016, 36, 67-71. [CrossRef] [PubMed]

42. Tachi, Y.; Hirai, T.; Miyata, A.; Ohara, K.; Iida, T.; Ishizu, Y.; Honda, T.; Kuzuya, T.; Hayashi, K.; Ishigami, M.; et al. Progressive fibrosis significantly correlates with hepatocellular carcinoma in patients with a sustained virological response. Hepatol. Res. 2015, 45, 238-246. [CrossRef] [PubMed]

43. George, S.L.; Bacon, B.R.; Brunt, E.M.; Mihindukulasuriya, K.L.; Hoffmann, J.; Di Bisceglie, A.M. Clinical, virologic, histologic, and biochemical outcomes after successful hcv therapy: A 5 year follow-up of 150 patients. Hepatology 2009, 49, 729-738. [CrossRef] [PubMed]

44. Martinez, S.M.; Foucher, J.; Combis, J.-M.; Métivier, S.; Brunetto, M.; Capron, D.; Bourlière, M.; Bronowicki, J.-P.; Dao, T.; Maynard-Muet, M.; et al. Longitudinal liver stiffness assessment in patients with chronic hepatitis c undergoing antiviral therapy. PLoS ONE 2012, 7, e47715. [CrossRef] [PubMed]

45. Poynard, T.; Moussalli, J.; Munteanu, M.; Thabut, D.; Lebray, P.; Rudler, M.; Ngo, Y.; Thibault, V.; Mkada, H.; Charlotte, F.; et al. Slow regression of liver fibrosis presumed by repeated biomarkers after virological cure in patients with chronic hepatitis C. J. Hepatol. 2013, 59, 675-683. [CrossRef] [PubMed]

(C) 2017 by the authors. Licensee MDPI, Basel, Switzerland. This article is an open access article distributed under the terms and conditions of the Creative Commons Attribution (CC BY) license (http:/ / creativecommons.org/licenses/by/4.0/). 